\title{
Energy Consumption and Sensitivity Analysis of Paddy Production under Different Farm Sizes in Southern Dry Zone of Karnataka, India
}

\author{
Prasanna Kumar, P.S.*, Chinnappa Reddy, B.V., Umesh, K.B. and Ranjith Kumar, P.S.
}

Department of Agricultural Economics, UAS, GKVK, Bangalore, Karnataka, India

*Corresponding author: shiprasannamk415@gmail.com

\begin{abstract}
The study was carried out to assess the energy use pattern and its efficiency in paddy production under different farm sizes in Karnataka. Data were collected from 90 sample farmers, by using a pretested schedule through personal interviews. The results indicated that the total energy used for producing paddy was 8,957 MJ per acre with an energy input cost of ₹ 17, 008 per acre. Among different components of energy use in paddy production, chemical fertilizers accounted for the highest amount of energy to the extent of $5240 \mathrm{MJ}$ per acre (including $\mathrm{N}, \mathrm{P}_{2} \mathrm{O}_{2}$ and $\mathrm{K}_{2} \mathrm{O}$ ). The sample farmers had used excess fertilizer energy of 2050, 349 and $60 \mathrm{MJ}$ per acre of nitrogen, phosphorous and potash respectively, as compared to the recommendation of package of practice. The elasticity coefficients provided by the Cobb-Douglas production function indicated that draught animals, labor, seeds, FYM and PPC were statistically significant among small farms. Irrespective of the size of farms, labour was significantly contributed to the output energy. Hence, the effective use of labour energy input plays an important role in paddy production. The ratio of MVP to MFC was less than one for fertilizers irrespective of the size group of farms indicated that fertilizer energy was over used in paddy production. Elasticity coefficients of different forms of energy indicated that impact of renewable energy sources was much higher than that of non-renewable energy sources in paddy production. Hence, to improve the paddy yield, economic performance of the crop and environmental sustainability, farmers have to use more of renewable energy. The energy efficiency showed that the energy ratio (6.98) and energy productivity (0.29) of small farmers were highest as compared to medium and large farmers. This implied that small farmers efficiently used energy vis-à-vis medium and large farmers.
\end{abstract}

Keywords: Energy use pattern, sensitivity analysis, renewable and non- renewable energy, energy efficiency and energy productivity

Rice (Oryza sativa) is the staple food of the population of Asia, Latin America, and Africa. It provides 35-60 per cent of the dietary calory requirement of more than 3 billion people (Fageria, et al. 2003). Globally, it is also the second most cultivated cereal after wheat. Unlike wheat, 95per cent of the world's rice is grown in less developed nations, particularly in Asia, Africa, and Latin America. China and India are the largest rice producing and consuming countries in the world. It has been estimated that by 2025, it is necessary to produce about 60 per cent more rice than what is currently produced to meet food needs of the growing world population. This could turn out to be a challenge as the land available for crop production is decreasing steadily due to urban growth and land degradation. Hence, increases in rice production will have to come from the same or an even less amount of land. This means appropriate rice production practices and technologies have to be adopted to improve rice yield per unit area (Fageria, 2007). It has been established that crop yields and food supplies are directly linked to the magnitude of energy use., Energy has turned out to be the most valuable input in agriculture in its various forms of mechanical (from machines, human labour, animal draft), chemical (fertilizer, 
pesticides, herbicides), electrical, heat, etc. (Stout, 1990; Pimentel, 1992).

The efficient use of the energy resources is vital for increasing productivity and aggregate production as the cost of energy in agriculture is increasing due to large scale shift from traditional sources to manufactured sources. Hence, examining energy efficiency and environmental impact of the production system is essential for sustainability of rural households. The approach facilitates researchers to estimate output-input ratio, relevant indicators and energy use patterns in an agricultural activity. Further, the energy audit paves way for generating sufficient data to establish functional forms to discern relationships among energy inputs and outputs. Identifying functional forms is an important step in quantification of elasticity coefficients of inputs on yield and production (Hatirli et al. 2006).

The energy use pattern in India for production of crops varies across different agro-climatic zones. The magnitude of energy use in the crop production varies with the availability of energy sources in a particular region and on the economic capacity of the farmers. In India, agriculture has transformed into a commercial entity, largely due to technological innovations in agriculture which call for large scale use of energy, therefore, it is imperative to carry out analysis of energy use in crop production system and to establish optimum energy input at different levels of productivity. This dimension assumes even greater importance due to the fact that there is a perceptible shift in the use of energy from natural sources to fossil sources of energy, which from sustainable point of view does not augur well for the country. Right source and appropriate mix of energy input into crop production is called from the view point of economic and environment. For example, through use machinery energy is environmentally detrimental, in case with other sources of energy is may reduce energy input, labour use, time and finally cost (Karale et al. 2008). Therefore, energy analysis is necessary from efficient management of scarce resources for enhancing the agricultural productivity. It would identify production practices that are economical and effective. Other benefits of energy analysis include determination of the energy invested in each stage of the production process (hence identifying the steps that require least energy inputs), to provide a basis for conservation and to aid in making sound management and policy decisions (Jekayinfa, 2006).

In India, studies on energy expenditure and returns in the energy analysis are few and far between. Therefore, analysis of energy-agriculture relationship is an important step in this direction especially for intensification of the cropping systems, which is considered to be the only means of raising agricultural output in land scarce situations (Abubakar and Ahmad, 2010). The main objective of this research paper is the quantification of the energy use pattern in different forms of energy in rice production.

\section{MATERIALS AND METHODS}

\section{Study area}

The study was conducted in Mandya district of Karnataka State, India in 2014-15 crop year. The district is located in the southern plain region of the state. The total geographical area of the district is 4, 98,244 hectares, out of which net sown area was 2 , 48,825 hectares. Agriculture is the main occupation of the people of the district and more than half of the total land area in the district is under agriculture. The total irrigated area is $1,16,901$ hectares, out of which an area of around 88,000 hectares is irrigated by Krishnaraja Sagar reservoir and around 16,000 ha by Hemavathi reservoir. The district is classified as Southern Dry Zone (SDZ) according to agro-climatic of Karnataka State.

The district enjoys tropical climate with temperature ranging between $160^{\circ}$ and $350{ }^{\circ} \mathrm{C}$. April is the hottest month and with the onset of southwest monsoon in June, the temperature drops considerably. December is the coldest month. The rainfall is generally uniform in the district except in the western sector where it is slightly higher. The normal rainfall of the district is $623 \mathrm{~mm}$. The soil structure in the district is mostly red sandy loam to red clay loam. The main crops grown in the district are paddy, sugarcane, sorghum, maize, cotton, finger millet, groundnut, horse gram and coconut. Mandya district was selected for the study because it is one of the major paddy growing districts in Karnataka and rice is the main source of income to farmers in this region. 


\section{Data collection and sampling procedure}

A multi-stage random sampling procedure was adopted for the selection of the taluks, villages and respondent farmers. In the first stage, three taluks were selected based on the highest area under irrigation. In the second stage, three villages were selected on the basis of highest irrigated area under paddy production from each of the selected taluks. In the final stage, ten farmers from each selected village comprising of small, medium and large farmers were selected randomly. Thus, the total sample size selected for the study was 90 farmers. The data on all inputs such as fertilizers, plant protection chemicals (PPC), weedicides, growth regulators, farmyard manure (FYM), power sources (human and draft animals) and agricultural machinery (power tiller, weeder, sprayer and thresher) used in the paddy production as well as yield of main and by-products were collected using a pretested schedule through personal interviews.

\section{Analytical framework}

The analytical framework consists of two approaches: (a) an accounting approach that provides basic measures of energy productivity, energy use efficiency and net energy balance. These are the widely used measures on energy (Heidari and Omid, 2011) and (b) an econometric estimation and sensitivity analysis of energy inputs. A brief description of the two approaches is given below.

\section{Energy accounting approach}

Energy consumption for different field operations in paddy production was classified as renewable and non-renewable energy sources. Renewable energy sources included human, labour, manure and seed, non-renewable sources comprised of diesel, electricity, chemicals, fertilizers, and machinery. Basic information on energy inputs and paddy yields were entered into excel spreadsheets and energy from inputs and outputs were calculated by converting the physical units of inputs and outputs into respective standard energy units using appropriate energy equivalents and finally they were expressed in Mega joule units as described in the succeeding actions.

\section{Energy accounting for chemical fertilizers}

The energy equivalent for a kilogram of nitrogen, phosphorus and potash (NPK) fertilizer was derived from the ratio of the elements $(\mathrm{N}, \mathrm{P}$ and $\mathrm{K})$ in a 50 $\mathrm{Kg}$ bag of the fertilizer. For example, if the farmer in the study area used a complex fertilizer of (NPK) 17:17:17 brand, then, for each nutrient element, its quantity in kilogram in a $50 \mathrm{~kg}$ bag was determined as below:

$$
\begin{aligned}
& N=\frac{17}{100} \times \frac{50}{1}=8.5 \\
& P=\frac{17}{100} \times \frac{50}{1}=8.5 \\
& K=\frac{17}{100} \times \frac{50}{1}=8.5
\end{aligned}
$$

From the literature, (Singh and Mittal, 1992) the energy equivalents for elemental $\mathrm{N}, \mathrm{P}$ and $\mathrm{K}$ were derived as; 60.60 MJ, 11.10 MJ and 6.70 MJ, respectively. The quantity of each element was converted to its energy equivalent as shown below:

$$
\begin{aligned}
& \mathbf{N}=60.60 \times 8.5=515.1 \mathrm{MJ} \\
& \mathbf{P}=11.10 \times 8.5=94.35 \mathrm{MJ} \\
& \mathbf{K}=6.70 \times 8.5=56.95 \mathrm{MJ} \\
& \text { Total }=666.4
\end{aligned}
$$

This implies that a $50 \mathrm{Kg}$ (use standard units) bag of NPK 17:17:17 fertilizer is equivalent to 666.4 MJ of energy, while a kilogram of the fertilizer is equivalent to $13.33 \mathrm{MJ}$ of energy.

\section{Indicators of energy consumption}

Energy use efficiency (energy ratio), energy productivity, specific energy (Mandal et al. 2002; Khan et al. 2004 and Yilmaz et al. 2005), and net energy were calculated, as shown in Eq. 1-4 which was used by Singh et al. 1997; Mandal et al. 2002; Mohammadi, Omid 2010.

(a) Energy ratio was defined as the ratio of output energy to input energy

$$
\text { Energy ratio }=\frac{\text { Energy output }(M J / \text { acre })}{\text { Energy input }(M J / \text { acre })}
$$

(b) Specific energy has been widely used in energy analysis to express the quantity of energy 
invested to produce a unit quantity of the product.

Specific Energy =

$\frac{\text { Energy input }(\mathrm{MJ} / \text { acre })}{\text { Physical output paddy }(\mathrm{Kg} / \text { acre })}$

(c) Energy productivity $(\mathrm{Kg} / \mathrm{MJ})$ measures the quantity of product produced per unit of input energy. This is the inverse of specific energy. This serves as an evaluator of efficient use of energy in the production system yielding a particular product. The following expression was used to compute the energy productivity.

Energy Productivity =

$\frac{\text { Physical output of paddy }(\mathrm{Kg} / \text { acre })}{\text { Energy input }(\mathrm{MJ} / \mathrm{acre})}$

(d) Net energy return is defined as the difference between output energy and input energy and expressed in MJ/acre.

Net Energy Return = Energy Output

(MJ /acre) - Energy Input (MJ /acre)

\section{Econometric estimation}

The relationship between energy inputs and output was investigated using a priori mathematical functional relationship. A production function summarizes the process of conversion of factors into a particular commodity. The Cobb-Douglass function is used widely in agriculture to quantify the relationship between various energy inputs and output of agricultural crops (Singh et al. 2004; Hatirli et al. 2006; Mobtaker et al. 2010). The Cobb-Douglas production function is expressed as below.

$$
Y=f(x) \exp (u)
$$

This function can further be expressed in the following log-linear form,

$$
\begin{aligned}
& \text { Model I: } \ln Y_{i}=\ln a+\sum_{j=1}^{n} b_{j} \ln \left(X_{i j}\right)+e_{i} \\
& (i=1,2 \ldots \ldots . ., n)
\end{aligned}
$$

Where,

$Y_{i}$, yield of paddyon the $\mathrm{i}^{\text {th }}$ farm

$X_{i,}$ inputs used in the paddy production

$A$, intercept term $b_{j}$ represent coefficients of inputs which are estimated from the model

$e_{i}$ error term

In this study, it is assumed that if there is no input energy, the output energy is also zero. Making this assumption requires excluding the intercept term (a) from Model I.

$$
\ln Y_{i}=\sum_{j=1}^{n} b_{j} \ln \left(X_{i j}\right)+e_{i} \quad(i=1,2 \ldots \ldots, n
$$

With this assumption the yield is a function of energy inputs only: human labor, draft animals, seeds, fertilizers, farm yard manure (FYM) and plant protection chemicals. Model I can be expressed as,

$$
\begin{aligned}
& \ln Y_{i}=b_{1} \ln \left(X_{1}\right)+b_{2} \ln \left(X_{2}\right)+b_{3} \ln \left(X_{3}\right)+b_{4} \ln \left(X_{4}\right) \\
& +b_{5} \ln \left(X_{5}\right)+b_{6} \ln \left(X_{6}\right)+b_{7} \ln \left(X_{7}\right)+e_{i}
\end{aligned}
$$

Where,

$Y=$ Output energy of crop (MJ /acre)

$X_{1}=$ Human labor $(\mathrm{MJ} / \mathrm{acre})$

$\mathrm{X}_{2}=$ Draught animal (MJ/acre)

$X_{3}=$ Machinery (MJ/acre)

$\mathrm{X}_{4}=$ Seeds (MJ /acre)

$X_{5}=$ Fertilizers (MJ /acre)

$X_{6}=$ Farm yard manure (FYM) (MJ/acre)

$X_{7}=$ Plant protection chemicals (PPC) (MJ/acre)

The effect of different forms of energy, namely, renewable and non-renewable energy on production was modeled by using the following equation (Rafiee et al. 2010, Heidari and Omid, 2011, Mobtaker et al. 2010).

Model II: $\ln Y_{i}=d_{1} \ln (R E)+d_{2} \ln (N R E)+e_{i}$

Where,

$Y_{i}=$ Output energy of crop

$b_{i}$ and $d_{i}=$ Coefficients of exogenous variables

$R E=$ Renewable energy

$N R E=$ Nonr-enewable energy

$e_{i}=$ Error term

By using the ordinary least square technique, equations 8 and 9 was estimated.

\section{Returns to scale}

Following the estimation of econometric model, 
the degree of returns to scale was determined to investigate the effect of energy inputs on output level. In farm production, returns to scale (RTS) refer to proportionate change in output subsequent to a proportional change in all inputs (where all inputs increase by a constant factor) (Rafiee et al. 2010). In the Cobb-Douglas production function, it is indicated by the sum of the elasticities derived in the form of regression coefficients. If the sum of the coefficients is greater than unity $\left(\sum_{i=1}^{n} b_{j}<1\right)$ then it is inferred as the increasing returns to scale (IRS). That means an increase in inputs may result in a greater proportionate increase in output than the input increase.

If the sum is less than unity $\left(\sum_{i=1}^{n} b_{j}<1\right)$ then it is inferred as the decreasing returns to scale (DRS).

That means an increase in inputs may result in an increase in output in less proportion than the input increase and if the result is unity $\left(\sum_{i=1}^{n} b_{j}=1\right)$ it shows the constant returns to scale. This implies the output change is constant at the rate of input change (Singh et al. 2004, Sara, et al. 2011).

\section{Sensitivity analysis}

The sensitivity of energy input use on yield of crops was analyzed to determine how the output is affected by the change in each energy input usage. For this purpose, the measure of marginal physical productivity (MPP), based on the response coefficients of the inputs was used. The MPP of a factor implies the change in the total output with a unit change in the factor input, assuming all other factors are fixed at their geometric mean level. A positive value of MPP of any input variable identifies the rate of total output increase with an increase in input; so, one should not stop increasing the use of variable input so long as the fixed resource is not fully utilized. The MPP of the various inputs was calculated using the $b_{j}$ of the various energy inputs as below.

$$
M P P x_{j}=\frac{G M(Y)}{G M\left(X_{j}\right)} \times b_{j}
$$

Where,

$$
M P P_{x j}=\text { Marginal physical productivity of } \mathbf{j}^{\text {th }} \text { input, }
$$

$b_{j}=$ Regression coefficient of $j^{\text {th }}$ input,

$G M(Y)=$ Geometric mean of yield and

$G M\left(X_{j}\right)=$ Geometric mean of $j^{\text {th }}$ input energy on per acrebasis

\section{RESULTS AND DISCUSSION}

Agriculture is both producer and consumer of energy. Use of energy is inevitable in crop production and its pattern depends on nature of crop, rainfed or irrigated and duration of the crop. The energy use pattern refers to the nature and quantum of energy input like human, draft animal, mechanical power (tractor, power tiller, irrigation pump), seeds, fertilizers, plant protection chemicals and micro nutrients used in crop production. in this study energy use pattern, associated costs and its efficiency in paddy production are analyzed and presented under the following heads.

\section{Energy use pattern in paddy cultivation in Southern Dry Zone (SDZ)}

The amount of energy inputs used by different types of farms (Table 1) in SDZ revealed that the farmers in the study area had used energy from ten different sources for paddy cultivation, namely, human, draught animals, machines, seeds, fertilizers, farm yard manure (FYM), micronutrients, growth regulators, weedicides and plant protection chemicals. The total energy expended for producing paddy was $8957 \mathrm{MJ}$ per acre with an energy input cost of ₹ 17, 008 per acre. Among the different energy sources, chemical fertilizers were the dominant source of energy contributing $5240 \mathrm{MJ}$ per acre (including $\mathrm{N}, \mathrm{P}_{2} \mathrm{O}_{2}$ and $\mathrm{K}_{2} \mathrm{O}$ ) which accounted for 59 per cent of the total energy utilized in paddy cultivation. Among fertilizers, the share of nitrogen nutrient was highest (50\%) in the energy use in paddy cultivation. An interesting pattern with respect to energy use across different farm sizes emerged that large farmers were able to use cheaper sources of energy machinery energy (20\%) than small farms ( $2 \%$ of machinery). As a result of this small farmers incurred higher parity cost of 2.43 as against 1.61 of large farms. The sample farmers had used excess fertilizer energy to the extent of 2050, 349 and $60 \mathrm{MJ}$ per acre in the form of nitrogen, phosphorous and potash respectively, as compared to the recommendations of package of practices (Table 2). It is a common practice in the 
Table 1: Energy use pattern and associated costs across different size group of farmers in paddy cultivation in SDZ

\begin{tabular}{|c|c|c|c|c|c|c|c|c|c|c|c|c|c|c|c|c|c|}
\hline \multirow{3}{*}{$\begin{array}{l}\text { Sl. } \\
\text { No. }\end{array}$} & \multirow{3}{*}{ Sources } & \multicolumn{4}{|c|}{ Small Farmer } & \multicolumn{4}{|c|}{ Medium Farmer } & \multicolumn{4}{|c|}{ Large Farmer } & \multicolumn{4}{|c|}{ Overall } \\
\hline & & \multirow{2}{*}{$\begin{array}{c}\frac{\text { Energy }}{\mathrm{MJ} /} \\
\text { acre }\end{array}$} & \multirow[b]{2}{*}{$\%$} & \multirow{2}{*}{$\frac{\text { Costs }}{\text { ₹/acre }}$} & \multirow[b]{2}{*}{$\%$} & \multirow{2}{*}{$\begin{array}{c}\text { Energy } \\
\text { MJ/ } \\
\text { acre } \\
\end{array}$} & \multirow[b]{2}{*}{$\%$} & \multirow{2}{*}{$\begin{array}{l}\text { Costs } \\
\text { ₹/acre }\end{array}$} & \multirow{2}{*}{\multicolumn{2}{|c|}{$\% \frac{\begin{array}{l}\text { Energy } \\
\mathrm{MJ} / \\
\text { acre }\end{array}}{}$}} & \multirow[b]{2}{*}{$\%$} & \multirow{2}{*}{$\begin{array}{l}\text { Costs } \\
\text { ₹/acre }\end{array}$} & \multirow{2}{*}{\multicolumn{2}{|c|}{$\% \begin{array}{c}\text { Energy } \\
\begin{array}{l}\mathrm{MJ} / \\
\text { acre }\end{array} \\
\end{array}$}} & \multirow[b]{2}{*}{$\%$} & \multirow{2}{*}{$\frac{\text { Costs }}{\text { ₹/acre }}$} & \multirow[b]{2}{*}{$\%$} \\
\hline & & & & & & & & & & & & & & & & & \\
\hline 1 & Human labour & & & & & & & & & & & & & & & & \\
\hline (a) & Men & 305 & 4 & 2918 & 17 & 260 & 3 & 2487 & 15 & 256 & 2 & 2451 & 14 & 274 & 3 & 2619 & 15 \\
\hline \multirow[t]{2}{*}{ (b) } & Women & 421 & 6 & 3020 & 18 & 350 & 4 & 2508 & 15 & 301 & 3 & 2156 & 12 & 357 & 4 & 2561 & 15 \\
\hline & Total & 726 & 10 & 5938 & 34 & 610 & 7 & 4996 & 31 & 557 & 5 & 4607 & 26 & 631 & 7 & 5180 & 30 \\
\hline 2 & Draught animals & 336 & 5 & 2495 & 14 & 277 & 3 & 1534 & 9 & 110 & 1 & 819 & 5 & 241 & 3 & 1616 & 10 \\
\hline 3 & Machine & 201 & 3 & 281 & 2 & 1427 & 16 & 1991 & 12 & 2523 & 23 & 3520 & 20 & 1383 & 15 & 1931 & 11 \\
\hline A & Operational energy & 1263 & 18 & 8713 & 51 & 2314 & 26 & 8520 & 53 & 3190 & 29 & 8946 & 51 & 2256 & 25 & 8727 & 51 \\
\hline 4 & Seeds & 437 & 6 & 713 & 4 & 418 & 5 & 683 & 4 & 415 & 4 & 678 & 4 & 423 & 5 & 691 & 4 \\
\hline 5 & Chemical Fertilizers & & & & & & & & & & & & & & & & \\
\hline (a) & $\mathrm{N}$ & 3610 & 51 & 3843 & 22 & 4376 & 50 & 4056 & 25 & 5436 & 50 & 5069 & 29 & 4474 & 50 & 4322 & 25 \\
\hline (b) & $\mathrm{P}_{2} \mathrm{O}_{5}$ & 514 & 7 & 548 & 3 & 523 & 6 & 485 & 3 & 675 & 6 & 630 & 4 & 571 & 6 & 554 & 3 \\
\hline \multirow[t]{2}{*}{ (c) } & $\mathrm{K}_{2} \mathrm{O}$ & 205 & 3 & 218 & 1 & 194 & 2 & 180 & 1 & 188 & 2 & 175 & 1 & 196 & 2 & 191 & 1 \\
\hline & Total Fertilizers & 4329 & 61 & 4608 & 27 & 5093 & 58 & 4720 & 29 & 6299 & 58 & 5874 & 33 & 5240 & 59 & 5068 & 30 \\
\hline 6 & Farm Yard Manure & 885 & 12 & 2653 & 15 & 504 & 6 & 1452 & 9 & 327 & 3 & 961 & 5 & 572 & 6 & 1689 & 10 \\
\hline 7 & Micronutrients & 45 & 1 & 62 & 0 & 64 & 1 & 89 & 1 & 86 & 1 & 118 & 1 & 65 & 1 & 89 & 1 \\
\hline 8 & Weedicides & 20 & 0 & 28 & 0 & 62 & 1 & 84 & 1 & 101 & 1 & 138 & 1 & 61 & 1 & 83 & 0 \\
\hline 9 & Growth Regulators & 0 & 0 & 0 & 0 & 0 & 0 & 0 & 0 & 53 & 0 & 211 & 1 & 18 & 0 & 70 & 0 \\
\hline 10 & $\begin{array}{l}\text { Plant protection } \\
\text { chemicals }\end{array}$ & 110 & 2 & 446 & 3 & 379 & 4 & 656 & 4 & 477 & 4 & 671 & 4 & 322 & 4 & 591 & 3 \\
\hline \multirow[t]{2}{*}{ B } & Total input energy & 5826 & 82 & 8510 & 49 & 6521 & 74 & 7683 & 47 & 7758 & 71 & 8651 & 49 & 6702 & 75 & 8282 & 49 \\
\hline & Grand total $(\mathrm{A}+\mathrm{B})$ & 7090 & 100 & 17223 & 100 & 8835 & 100 & 16204 & 100 & 10948 & 100 & 17597 & 100 & 8957 & 100 & 17008 & 100 \\
\hline $\mathrm{C}$ & Parity of cost $(₹ / M J) *$ & & 2.4 & & & & 1.8 & 83 & & & 1.61 & & & & 1.9 & & \\
\hline
\end{tabular}

Note: * Ratio of cost to input energy expressed in ₹/ MJ.

Table 2: Comparison of energy use with recommendations as per package of practice for paddy in SDZ of Karnataka

\begin{tabular}{lccccc}
\hline \multirow{2}{*}{ S1. No. } & \multirow{2}{*}{ Particulars } & \multirow{2}{*}{ Physical terms } & \multicolumn{3}{c}{ Energy used (MJ/acre) } \\
\cline { 3 - 6 } & & 25 & Recommended level of energy & Actual Energy used & Excess/ deficit \\
\hline a) & Seeds $(\mathrm{Kg})$ & 40 & 367.5 & 423 & 56 \\
b) & $\mathrm{N}(\mathrm{Kg})$ & 2424 & 4474 & 2050 \\
c) & $\mathrm{P}(\mathrm{Kg})$ & 222 & 571 & 349 \\
d) & $\mathrm{K}(\mathrm{Kg})$ & 20 & 134 & 196 & 62 \\
e) & FYM (Kg) & 4000 & 1200 & 572 & -628 \\
f) & Yield (Kg) & 2500 & 36425 & 28692 & -7733 \\
\hline
\end{tabular}

study region to use higher quantities of fertilizers especially that of nitrogen to boost paddy crop yields. Similar results were indicated by Pishgar et al. (2011) and Hamedani, et al. (2011) who reported that farmers used chemical fertilizers in greater in paddy production in Guilan province of Iran.
With respect to other sources of energy, machinery energy was used to the extent of 15 percent in the performance of various operations in paddy production. However, other sources of energy accounted for a smaller proportion of total energy use in paddy. Human, farm yard manure, seeds, 
plant protection chemicals, draught animals, micro nutrients, weedicides and growth regulators accounted for $7,6,4,4,5,1,1$, and 0.01 per cent, respectively, to the total energy use in paddy production. Results indicated that fertilizers (especially nitrogen) and machinery management seemed to be the important areas for improving energy efficiency. By using fertilizers based on the need, applying farmyard or green manure and planting leguminous species, the magnitude of chemical energy use in paddy production can be reduced substantially which could translate into direct cost savings. To achieve the economy in the machine energy used, operator skills have to be increased in addition to using machinery with full field capacity to reduce the time and diesel fuel consumption.

The total energy utilized for paddy cultivation was highest among large farmers (10,948 MJ/ acre) followed by medium (8,835 MJ/acre) and small farmers $(7,090 \mathrm{MJ} / \mathrm{acre})$. Further, energy utilized by large farmers from fertilizers $(6,299$ $\mathrm{MJ} /$ acre), machine (2523 MJ/acre), plant protection chemicals (477 MJ/acre), micronutrients (101 $\mathrm{MJ} / \mathrm{acre}$ ), weedicides (86 MJ/acre) and growth regulators (53 MJ/acre) was highest vis-à-vis small and medium farmers. It can be inferred that use of chemical energy varied positively with the farm size. Two reasons can be attributed to explain this pattern, lack of knowledge among farmers about the recommended package of practices and nutrient based subsidies on chemical fertilizers. Due to higher magnitude of subsidies for nitrogen fertilizer extended by the central government in India, are indirectly encouraged farmers to apply larger quantities of nitrogen fertilizer for paddy crop. Therefore, higher level of energy was expressed than recommended level. One interesting result observed from the Table 1 is that large farmers used largest proportion of energy (23\%) from mechanical sources vis-à-vis small and medium farmers who used about 3 and 16 percent of mechanical energy in the total energy. Although from operational efficiency point of view, it is desirable, but from view point of sustainability and ecological dimensions, use of greater $r$ magnitude of mechanical energy is detrimental to the soil ecology. Coupled with this is the declining rate of energy use from FYM among large farmers as they derived only 3 per cent from this source as against 12 and 6 percent among small and medium farmers. From ecology and environmental point of view, use of this energy is needed on larger proportions and small farmers are more inclined towards ecology and environment although use of this energy is guided by lack of economic power to buy costly inputs of fertilizer and farm machinery. As discussed previously, unit cost of energy from FYM was greater than that of mechanical sources, hence large farmers relay more on mechanical energy than on FYM this is a paradox that subsidy given to fertilizers us underlying the ecology and environment.

The energy utilized from biological (renewable) sources such as human, draught animals, seeds and farm yard manure was higher among small and medium farmers than large farmers. This could be attributed to the use of family labor and farm based inputs in larger quantities by small and medium farmers rather than commercial sources of energy. This implied a better management of biological sources of energy by smaller farmers. In a study carried out by Chauhan et al. (2006) in paddy production they inferred that potentially good operating practices which included utilization of chemical fertilizer, human labor and seed sources led to the efficient paddy production.

The incidence of energy costs across different size groups of farmers indicated that in paddy cultivation the total cost of energy input was least in the case of medium (₹ 16,204/acre) farmers followed by small ( $₹ 17,223$ /acre) and large farmers (₹ 17,597/acre) (Table 1). Further, a similar pattern was observed in the case of the operational and input energy cost. Optimal combination of labor, draught animals and machine energy sources used by medium farmers in paddy cultivation might have contributed to this phenomenon the lowest expectation on energy inputs.

Operation of scale economies was observed in the labor and draught animal cost decreased with increased farm size among large farmers as they did not possess adequate endowment of these resources commensurate with farm size. As a result, the machine and fertilizer cost increased among large farmers. The parity of costs (ratio of costs to energy) indicated that the large farmers ( $₹ 1.61 / \mathrm{MJ}$ ) were the most efficient in energy use as compared to medium (₹ $1.83 / \mathrm{MJ}$ ) and small 
farmers (₹ 2.43/MJ). The low parity cost among large farmers was due to the use of higher level of mechanical energy than biological sources of energy. Through the parity costs of machine is lower, use of these resources might have negative impact on agricultural sustainability. Hence, for increasing the energy efficiency in agriculture and sustainability the use of the optimum contribution of biological and non-biological energy sources is recommended in which greater emphasis needs to be given to biological sources.

\section{Analysis of different forms of energy in paddy cultivation in SDZ}

The energy consumed in agriculture can be viewed in the form of renewable and non-renewable energy sources. As indicated in the Table 3, the nonrenewable energy forms accounted for 79 per cent of the total energy input for paddy cultivation, while only 21 per cent came from the renewable energy forms. Use of higher magnitude of non-renewable energy forms in paddy could be due to their lower cost (due to subsidy) at ₹ 1.10/ MJ) vis-à-vis renewable sources whose cost was ₹ 4.91 per MJ of energy. Ibrahim and Ibrahim, (2012) also indicated that non-renewable energy sources accounted for major share in rice production in Nasarawa state, Nigeria. They reported that paddy production was mainly dependent on non-renewable input especially herbicide. They recommended the introduction of integrated weed management system to reduce the excessive use of herbicide for weed control. Farmers should be educated on the negative effect of excessive use of herbicides on the environment and the long run impact on climate change.

Several researchers have found similar results that the share of non-renewable energy was greater than that of renewable energy consumption in cropping systems (Esengun et al. 2007; Ozkan et al. 2007; Kizilaslan 2009 and Komleh et al. 2011). Results of these studies indicated that paddy production was mostly depending on fossil energy sources. The farmers had used more of non-renewable energy sources due subsidized price of these energy sources. This could be harmful to the environment and ecology in the long run. Therefore, paddy farmers need to switch over to renewable energy sources in paddy production, although such an effort could be painful and costly affair. However, many external factors come in the way of adoption of environmentally benign energy sources such as dwindling availability of FYM as livestock number are declining and labour scarcity is mounting for agricultural operations.

The paddy cultivation in the study area was mostly dependent on commercial, non-renewable and indirect energy forms which do not augur well for sustainability of paddy production and soil ecology of agricultural lands. The overall parity cost of indirect (₹ 1.58/MJ), non-renewable (₹ 1.28/ $\mathrm{MJ}$ ) and commercial energy ( $₹ 1.48 / \mathrm{MJ})$ forms were substantially much lower than direct, renewable and non-commercial energy forms whose parity cost were ₹ 8.75/MJ, ₹ 3.53/MJ and ₹ 5.87/MJ respectively. The net energy available per unit was substantially lower than that of former leading to higher cost of energy unit. This biased parity in the energy costs

Table 3: Sources of energy and associated costs across different size group of farmers in paddy cultivation in SDZ

\begin{tabular}{|c|c|c|c|c|c|c|c|c|c|c|c|c|c|c|c|c|c|}
\hline \multirow{3}{*}{$\begin{array}{l}\text { Sl. } \\
\text { No. }\end{array}$} & \multirow{3}{*}{ Sources } & \multicolumn{4}{|c|}{ Small Farmer } & \multicolumn{4}{|c|}{ Medium Farmer } & \multicolumn{4}{|c|}{ Large Farmer } & \multicolumn{4}{|c|}{ Overall } \\
\hline & & \multirow{2}{*}{$\begin{array}{c}\text { Energy } \\
\text { MJ/ } \\
\text { acre }\end{array}$} & \multirow[b]{2}{*}{$\%$} & \multirow{2}{*}{$\begin{array}{l}\text { Costs } \\
\text { ₹/acre }\end{array}$} & \multirow[b]{2}{*}{$\%$} & \multirow{2}{*}{$\begin{array}{c}\text { Energy } \\
\text { MJ/ } \\
\text { acre }\end{array}$} & \multirow{2}{*}{$\%$} & \multirow{2}{*}{$\begin{array}{l}\text { Costs } \\
\text { ₹/acre }\end{array}$} & \multirow[b]{2}{*}{$\%$} & \multirow{2}{*}{$\begin{array}{l}\text { Energy } \\
\text { MJ/acre }\end{array}$} & \multirow[b]{2}{*}{$\%$} & \multirow{2}{*}{$\begin{array}{l}\text { Costs } \\
\text { ₹/acre }\end{array}$} & \multirow[b]{2}{*}{$\%$} & \multirow{2}{*}{$\begin{array}{c}\text { Energy } \\
\text { MJ/ } \\
\text { acre }\end{array}$} & \multirow[b]{2}{*}{$\%$} & \multirow{2}{*}{$\begin{array}{l}\text { Costs } \\
\text { ₹/acre }\end{array}$} & \multirow[b]{2}{*}{$\%$} \\
\hline & & & & & & & & & & & & & & & & & \\
\hline 1 & Renewable energy & 2384 & 34 & 11799 & 69 & 1810 & 20 & 8664 & 53 & 1410 & 13 & 7064 & 40 & 1868 & 21 & 9176 & 54 \\
\hline \multirow[t]{3}{*}{2} & $\begin{array}{c}\text { Non - Renewable } \\
\text { energy }\end{array}$ & 4706 & 66 & 5424 & 31 & 7025 & 80 & 7540 & 47 & 9538 & 87 & 10533 & 60 & 7090 & 79 & 7832 & 46 \\
\hline & $\begin{array}{l}\text { Parity of cost RE } \\
\text { (₹/MJ) }\end{array}$ & \multicolumn{4}{|c|}{4.95} & \multicolumn{4}{|c|}{4.79} & \multicolumn{4}{|c|}{5.01} & \multicolumn{3}{|c|}{4.91} & \\
\hline & $\begin{array}{c}\text { Parity of cost NRE } \\
\text { (₹/MJ) }\end{array}$ & \multicolumn{3}{|c|}{1.15} & & \multicolumn{4}{|c|}{1.07} & \multicolumn{4}{|c|}{1.10} & \multicolumn{3}{|c|}{1.10} & \\
\hline
\end{tabular}


is inducing farmers to go for cheaper sources of energy.

\section{Econometric estimation of energy consumption in paddy cultivation}

Energy combination in paddy production is influenced by various factors and their impact on paddy production was analyzed in terms of energy input and output through regression analysis. The output energy of paddy (endogenous variable) was assumed as a function of human labor, draught animals, machinery, seeds, fertilizers and farmyard manure (exogenous variables). The Co-efficient of determination $\left(\mathrm{R}^{2}\right)$ was 0.99 in all the three types of farms indicating the goodness of fit of the model (Table 4). This means that 99 per cent of the total variation in the paddy output enregy was explained by variation in the independent variable included in the model.

The OLS estimates of Cobb-Douglas production function indicated that variables draught animals, labor, seeds, FYM and PPC were statistically significant among small farms. This implies that with one percent increase in the use of these input energy levels from their geometric mean levels, the output energy increases by $0.36,0.27,0.24,0.09$ and 0.09 per cent respectively. In all the size group of farmers, labour had significantly contributed to the output energy in paddy production. Hence, the effective use of labour energy input plays an important role in paddy production. The medium and large farmers had expressed decreasing returns to scale for labour indicating near optimality in the production of paddy. Hence, it is recommended the medium and large farmers to use the energy inputs optimally to increase the paddy output.

\section{Allocative efficiency of energy use in paddy cultivation}

Allocative efficiency, which is measured as the ratio of MVP/MFC of energy use in paddy cultivation (Table 5) indicated that except fertilizers (0.04) and FYM (0.06) in small farms, the ratio of MVPMFC for all other energy inputs of labour (2.38), draught animals was more than unity implying that a unit increase in each input would increase the energy output, meaning that all these inputs were underutilized. Hence, the small farmers are suggested using more of these energy inputs to increase profit in paddy production. In contrast, the small farmers had over used chemical fertilizers (0.04) and FYM (0.06). Hence, small farmers need to consider reduction in the use of fertilizers and FYM to increase the economic performance of paddy cultivation. In medium sized farms, the ratio of labour, machinery and seeds were more than unity suggesting that the medium farmers

Table 4: Estimates of Cobb-Douglas production function for energy inputs in paddy production

Dependent variable: Output energy (MJ/acre)

\begin{tabular}{|c|c|c|c|c|c|c|c|}
\hline \multirow{2}{*}{\multicolumn{2}{|c|}{ Exogenous variables }} & \multicolumn{2}{|c|}{ Small farmer } & \multicolumn{2}{|c|}{ Medium farmer } & \multicolumn{2}{|c|}{ Large farmer } \\
\hline & & Coefficient & t-ratio & Coefficient & t-ratio & Coefficient & t-ratio \\
\hline \multicolumn{8}{|c|}{ Model 1: $\ln Y_{i}=b_{1} \ln \left(X_{1}\right)+b_{2} \ln \left(X_{2}\right)+b_{3} \ln \left(X_{3}\right)+b_{4} \ln \left(X_{4}\right)+b_{5} \ln \left(X_{5}\right)+b_{6} \ln \left(X_{6}\right)+b_{7} \ln \left(X_{7}\right)$} \\
\hline 1. Labor & & $0.27^{* *}$ & 3.72 & $0.22^{* *}$ & 2.45 & $0.37^{* *}$ & 4.91 \\
\hline 2. Draught Anima & & $0.36^{* *}$ & 4.11 & -0.01 & -0.25 & 0.02 & 0.62 \\
\hline 3. Machinery & & 0.06 & 1.41 & $0.20^{* *}$ & 2.96 & $0.11^{*}$ & 1.96 \\
\hline 4. Seeds & & $0.24^{* *}$ & 3.04 & 0.13 & 0.88 & 0.13 & 1.38 \\
\hline 5. Fertilizers & & 0.05 & 1.15 & $0.33^{* *}$ & 4.32 & $0.11^{* *}$ & 4.84 \\
\hline 6. FYM & & $0.09^{* *}$ & 2.53 & -0.05 & -1.12 & 0.00 & -0.02 \\
\hline 7. PPC & & $0.09^{* *}$ & 3.32 & 0.09 & 1.35 & $0.23^{* *}$ & 4.66 \\
\hline $\mathrm{R}^{2}$ & & 0.99 & & 0.99 & & 0.99 & \\
\hline Returns to Scale & $\sum_{=1}^{n} b_{j}$ & 1.16 & & 0.90 & & 0.96 & \\
\hline
\end{tabular}

Note: **Significant at $1 \%$ level; *Significant at $5 \%$ level. 
Table 5: Allocative efficiency of energy inputs use and sensitivity analysis in paddy production

Dependent variable: Output energy (MJ/acre)

\begin{tabular}{lcccccccccccc}
\hline \multicolumn{1}{c}{$\begin{array}{c}\text { Exogenous } \\
\text { variables }\end{array}$} & \multicolumn{4}{c}{ Small farmer } & \multicolumn{4}{c}{ Medium farmer } & \multicolumn{4}{c}{ Large farmer } \\
\cline { 2 - 13 } & MPP & MVP & MFC & $r$ & MPP & MVP & MFC & $r$ & MPP & MVP & MFC & $r$ \\
\hline 1. Labor & 0.22 & 285 & 120 & 2.38 & 0.17 & 256 & 120 & 2.13 & 0.29 & 367 & 120 & 3.06 \\
2. Draught Animal & 1.19 & 1569 & 600 & 2.62 & 0.08 & 126 & 600 & 0.21 & 0.28 & 351 & 600 & 0.58 \\
3. Machinery & 0.83 & 1097 & 700 & 1.57 & 0.52 & 779 & 700 & 1.11 & 0.23 & 292 & 700 & 0.42 \\
4. Seeds & 0.22 & 289 & 30 & 9.71 & 0.11 & 169 & 24 & 7.02 & 0.11 & 145 & 24 & 6.05 \\
5. Fertilizers & 0.03 & 40 & 966 & 0.04 & 0.18 & 272 & 1150 & 0.24 & 0.06 & 73 & 1500 & 0.05 \\
6. FYM & 0.04 & 50 & 885 & 0.06 & -0.02 & -29 & 863 & -0.03 & 0.00 & 0 & 879 & 0.00 \\
7. PPC & 0.73 & 960 & 503 & 1.91 & 0.21 & 312 & 320 & 0.98 & 0.50 & 631 & 120 & 3.06 \\
\hline
\end{tabular}

Note: $r=M V P / M F C$

Where, $r=$ Efficiency ratio; $M V P=$ Marginal value product of variable inputs; $M F C=$ Marginal factor cost (price per unit of inputs); (2.16), machinery (1.57) seeds (9.71) and PPC (1.91).

Table 6: Estimates of Cobb-Douglas production for different forms of energy inputs in paddy production

Output energy (MJ/acre)

\begin{tabular}{lcccccc}
\hline \multirow{2}{*}{ Exogenous variables } & \multicolumn{2}{c}{ Small farmer } & \multicolumn{2}{c}{ Medium farmer } & \multicolumn{2}{c}{ Large farmer } \\
\cline { 2 - 7 } & Coefficient & t-ratio & Coefficient & t-ratio & Coefficient & t-ratio \\
\hline Model II: $\ln Y_{i}=b_{1} \ln (R E)+b_{2} \ln (N R E)$ & & & & & & \\
\hline 1. Renewable energy & $0.28^{* *}$ & 6.66 & $0.68^{* *}$ & 12.16 & $0.41^{* *}$ & 12.91 \\
2. Non-renewable energy & $0.19^{* *}$ & 3.23 & $0.12^{* *}$ & 2.66 & $0.07^{*}$ & 2.38 \\
$\mathrm{R}^{2}$ & 0.99 & & 0.99 & & 0.99 & \\
Returns to scale & 0.47 & & 0.80 & & 0.49 \\
\hline
\end{tabular}

Note: **Significant at $1 \%$ level; *Significant at $5 \%$ level.

had potential to increase the paddy yield by using higher level of these energy inputs, among large farmers, labour (3.06), seeds (6.05) and PPC (3.06) were underutilized. This indicated that the large farmers had potential to augment the paddy yield by increasing the use of these energy inputs.

\section{Econometric estimation of different forms of energy in paddy cultivation}

The relationship between renewable (RE) and nonrenewable (NRE) energy forms on output energy of paddy was investigated by models II. The results of model II in Table 6 indicated that both renewable and non-renewable energy inputs contributed significantly for paddy yield in all the farms. However, the significant impact of renewable energy sources was much higher than non-renewable energy sources in paddy production. Hence, to improve the paddy yield, economic performance of the crop and environmental sustainability farmers may consider use of renewable energy in larger quantities. Returns to scale in both the models II) showed decreasing return to scale irrespective of farm size. Both the models had good fit as the coefficient of determination was 0.99 in all the farms irrespective of farm size.

\section{Energy efficiency and economic analysis of paddy cultivation in SDZ}

The energy efficiency indicators in paddy cultivation were presented in Table 7 . The energy ratio various varied from 4.36 to 6.96 in different size groups of farmers. This variation in energy efficiency (energy ratio) is explained in terms of sources and nature of energy inputs used in paddy cultivation. It is noteworthy that the ratio can be increased by increasing the crop yield or by decreasing specific energy consumption (input management). The energy ratio (6.98) and energy productivity (0.29) of small farmers was more as compared to medium 
and large farmers. This implied that small farmers had more efficiently used energy as compared to medium and large farmers. This is explained by higher output energy realized and low specific energy requirement by small farmers. The higher output realized by small farmers was due to use of right combinations of labour, draught animal and mechanical energy sources. The small farmers had used more of farm based input like farmyard manure which is less expensive instead of chemical fertilizers. This result was in conformity with study of Guruswamy (1997).

The economic analysis showed that the net returns (₹ 20,483/acre) and returns per rupee of input energy cost (2.19) were highest among small farms vis-a-vis large and medium farmers. The higher paddy yield and low specific energy use were due to use of more of farm based input like farmyard manure which is less expensive instead of chemical fertilizers by small farmers which led to higher energy use efficiency and better returns per rupee of input cost. As evident from energy indices and economic analysis of paddy cultivation, small farms were more successful in energy productivity, energy use efficiency and economic performance as compared to medium and large farmers. Hence, the medium and large farmers may try to use more of farm based input like farmyard manure (although its availability is scarce) and reduce the excess application of chemical fertilizers to improve the energy efficiency and to realize higher profit in paddy cultivation.

\section{REFERENCES}

Chauhan, N.S., Mohapatra, P.K.J. and Pandey, K.P. 2006. Improving energy productivity in paddy production through benchmarking: an application of data envelopment analysis. Energy Conversion and Management, 47: 1063-1085.

Esengun, K., Erdal, G., Erdal, H. and Gunduz, O. 2007. Energy use and economic analysis of sugar beet production in Tokat province of Turkey. Energy, 32: 35-41.

Fageria, N.K., Slaton, N.A. and Baligar, V.C. 2003. Nutrient management for improving lowland rice productivity and sustainability. Advances in Agronomy, 80: 63-152.

Fageria, N.K. 2007. Yield Physiology of Rice. Journal of Plant Nutrition, 30: 843-879.

Guruswamy, 1997. Sub Project on Research on Mechanization of Dry Land Agriculture. Univ. Agric. Sci., Dharwad.

Hamedani, S.R., Keyhani, A. and Alimardani, R. 2011. Energy use patterns and econometric models of grape production in Hamadan province of Iran. Energy, 36: 6345-6351.
Hatirli, S.A., Ozkan, B. and Fert, C. 2006. Energy inputs and crop yield relationship in greenhouse tomato production. Renewable Energy, 31: 427-438.

Heidari, M.D. and Omid, M. 2011. Energy use patterns and econometric models of major greenhouse vegetable productions in Iran. Energy, 36: 220-225.

Ibrahim, H.Y. and Ibrahim, H.I. 2012. Energy use analysis for rice production in Nasarawa state, Nigeria. Tropical and Subtropical Agro-Ecosystems, 15: 649 - 655.

Jekayinfa, S.O. 2006. Energy consumption pattern of selected mechanized farms in South-western Nigeria. Agricultural Engineering International: the CIGR Journal. Vol. VIII. Manuscript EE 06001.

Karale, D.S., Khambalkar, V.P., Bhende, S.M., Sharddha, B. Amle and Pranali, S. Wankhede, 2008, Energy Economic of Small Farming Crop Production Operations. World J. Agric. Sci., 4(4): 476-482.

Khan, M.A., Ahmad, S., Hussain, Z., Yasin, M., Aslam, M. and Majid, R. 2004. Efficiency of water and energy use for production of organic wheat. Journal of Science, Technology and Development, 24: 25-29.

Kizilaslan, H. 2009. Input-output energy analysis of cherries production in Tokat province of Turkey. Applied Energy, 86: $1354-1358$.

Komleh, P.S.H., Sefeedpari, P. and Rafiee, S. 2011. Energy and economic analysis of rice production under different farm levels in Guilan province of Iran. Energy, 36: 5824-5831.

Mandal, K.G., Saha, K.P., Ghosh P.K. and Hati, K.M. 2002. Bandyopadhyay, bioenergy and economic analysis of soybean-based crop production system in central India. Biomass and Bio-energy, 23: 337-345.

Mobtaker, H.G., Keyhani, A., Mohammadi, A., Rafiee, S. and Akram, A. 2010. Sensitivity analysis of energy inputs for barley production in Hamedan Province of Iran. Agriculture, Ecosystems \& Environment, 137: 367-372.

Mohammadi, A. and Omid. M. 2010. Economic analysis and relation between energy inputs and yield of greenhouse cucumber production in Iran. Applied Energy, 87(1): 191-96.

Ozkanb, fert, C. and Karadeniz, F. 2007. Energy and cost analysis for green house and open-field grape production. Energy, 32: 15.

Pimentel, D. 1992. Energy Inputs in Production Agriculture. Energy in Farm Production, Elsevier and Amsterdam, pp. 13-29.

Pishgar-Komleh, S.H., Sefeedpari, P. and Rafiee, S. 2011. Energy and economic analysis of rice production under different farm levels in Guilan province of Iran. Energy, 36: 5824-5831.

Singh, G., Singh, S. and Singh, J. 2004. Optimization of energy inputs for wheat crop in Punjab. Energy Conversion and Management, 45: 453-465.

Singh, S. and Mittal, J.P. 1992. Energy in Production Agriculture.1st Edition. Mittal Publication, New Delhi, pp.166. 
Singh, S., Verma, S.R. and Mittal, J.P. 1997. Energy requirements for production of major crops in India. Agricultural Mechanization in Asia, Africa, and Latin America, 28: 13-27.

Stout, B.A. 1990. Handbook of Energy for World Agriculture. Elsevier Applied Science, London.
Unakitan, G., Hurma, H. and Yilmaz, F. 2010. An analysis of energy use efficiency of canola production in Turkey. Energy, 35: 3623-3627.

Yilmaz, I., Akcaoz, H. and Ozkan, B. 2005. An analysis of energy use and input costs for cotton production in Turkey. Renewable Energy, 30: 145-155. 